\title{
Research on the Evaluation Method of Diversified Teaching in Higher Vocational Colleges
}

\author{
Haiyan $\mathrm{Liu}^{1}, \mathrm{Xiaomin} \mathrm{Liu}^{2, *}, \mathrm{Li} \mathrm{Guo}^{1}$, Zhenhua $\mathrm{Xu}^{1}$ \\ ${ }^{I}$ School of Computer \& Communication Engineering, Beijing Information Technology College, BeiJing 100018, \\ China \\ ${ }^{2}$ Water Conservancy and Civil Engineering College of Inner Mongolia Agricultural University, Hohhot 010018, \\ China \\ "Corresponding author. Email: lhy_lj@sina.com
}

\begin{abstract}
Aiming at the problems of single teaching evaluation method and lack of students' participation in the evaluation content in higher vocational education, this paper constructs a method for schools, colleges, teachers and students to jointly participate in the development of teaching evaluation index. The teaching evaluation method consists of teachers' teaching evaluation and students' learning evaluation. In the aspect of students' learning evaluation, process evaluation and summary evaluation are combined to make students' learning evaluation more fair, timely and comprehensive. At the same time, teachers can understand students' learning situation in time, improve teaching effect and promote students' learning.
\end{abstract}

Keywords: Higher Vocational Colleges, Diversified Teaching Classroom Instruction, Teaching Evaluation.

\section{INTRODUCTION}

There are many disadvantages in traditional teaching evaluation. The teaching evaluation of students is a topdown evaluation [1]. It is difficult for teachers and students and parents to interact with each other and play a positive incentive role. Moreover, the evaluation method is single. The evaluation of students is mainly based on paper homework and test scores. Most of them are result evaluation and lack of process or formative evaluation. In the network environment, students prefer the evaluation method of digital age, interesting evaluation method and positive incentive evaluation method. The existing teaching evaluation content mainly focuses on students' subjective feelings and lacks objective quantitative analysis [2]. Many evaluation questions do not guide the evaluators to pay attention to the teaching implementation, but let them give fuzzy grade evaluation to the more abstract concepts such as teaching concept, teaching ability and so on. These teaching terms are not easy to operate, which makes the teaching evaluation and teachers' teaching behavior cannot be corresponding one by one, and the evaluation results are not clear [3]. At the same time, the existing evaluation content lacks the participation of students, which is basically the evaluation method formulated by teachers, and cannot reflect the students' evaluation of teachers' teaching.

In this paper, the evaluation strategy, construction principle, evaluation index system and evaluation content are researched. This paper takes vocational colleges in Beijing as the research object, adopts the methods of literature review, questionnaire survey and other research methods, takes into account the diversity and difference design of evaluation index, combines process evaluation with general evaluation, and constructs measurable teaching evaluation content, so as to improve the evaluation of teaching effect. At the same time, it also enables teachers to understand students' learning situation in time, improve teaching effect and promote students' learning.

\section{THE MAKING METHOD OF TEACHING EVALUATION INDEX}

Teaching evaluation index mainly includes teachers' teaching evaluation and students' learning evaluation. The making method of evaluation index is shown in Figure 1. In the process of setting indicators, schools, departments, teachers and students are involved. The requirements of the school for the evaluation of teachers and students must be reflected in the index content. The 
participation of departments is to reflect the requirements of different majors for teachers' teaching and students' learning. The participation of teachers is to reflect the requirements of different courses for teaching evaluation. The participation of students is mainly to ensure that students fully understand the evaluation standards.

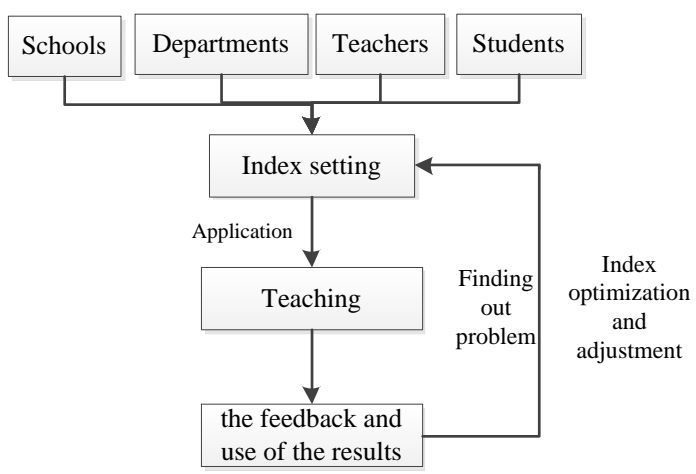

Figure 1 The Process of making the teaching evaluation index

In Figure 1, the first step is to determine the specific content of teaching evaluation index. In the process of making the indicators of teachers' teaching evaluation, students and teachers' opinions on the contents of teachers' teaching evaluation are solicited through questionnaires. For the evaluation of students' learning, students' opinions on the evaluation content are obtained through questionnaires. Teachers then make the content of students' learning evaluation according to students' opinions and the accumulated experience in daily teaching. According to the results of the survey and the requirements of the school for teachers' teaching and students' learning, the contents of the one-level and twolevel indicators are determined and the connotation of each level indicator is clarified. Then, the determined evaluation indicators are applied to teaching, and the indicators are tracked and evaluated. Finally, the teaching evaluation indicators need to be recognized by teachers and students, and the problems of the indicators are solved and optimized through the result feedback of teaching practice[4-5].

\section{THE DETERMINATION OF TEACHING EVALUATION INDEX}

\subsection{The Determination of Teachers' Teaching Evaluation Index}

The evaluation of teachers' teaching should include teachers' content and students' content. Teaching involves the integrity of teaching contents, the rationality of teaching methods, the advanced nature of teaching mode, and the teaching effect. The teaching effect mainly includes the effect of students mastering the course content, stimulating their interest in learning, and improving their ability of active learning and problem analysis. With the development of information technology, teaching mode is not only limited to classroom teaching, but also needs the combination of online and offline to expand students' knowledge, cultivate students' self-learning ability and problemsolving ability. This requires teachers to prepare a large number of resources related to the course before class, and present them on the platform in the form of animation, micro class, PPT, video, etc.. The use of curriculum resources need to be evaluated.

The one-level indicators of teacher evaluation include fundamental rules, teaching organization, teaching content, teaching methods, teaching mode and teaching effect, as shown in Table 1.

Table 1. Teacher teaching evaluation index

\begin{tabular}{|c|c|c|}
\hline Index category & One-level index & Two-level index \\
\hline \multirow{16}{*}{$\begin{array}{l}\text { Teacher teaching } \\
\text { evaluation index }\end{array}$} & \multirow{2}{*}{ fundamental rules } & The language is clear and fluent. \\
\hline & & Lectures are infectious \\
\hline & \multirow[t]{3}{*}{ teaching organization } & $\begin{array}{l}\text { Teachers can control rhythm of classroom teaching and can effectively } \\
\text { attract students' learning attention. }\end{array}$ \\
\hline & & $\begin{array}{l}\text { The form of classroom interaction (teacher-student interaction, student - } \\
\text { student interaction) is various forms, scientific and effective. }\end{array}$ \\
\hline & & Teachers can maintain the classroom order effectively. \\
\hline & \multirow[t]{5}{*}{ Teaching content } & Clear logic and comprehensive coverage \\
\hline & & Rich curriculum resources \\
\hline & & Closely combined with new knowledge, new technology and new situation \\
\hline & & The information in class is moderate. \\
\hline & & Homework \\
\hline & \multirow[t]{2}{*}{ teaching methods } & $\begin{array}{l}\text { The teaching methods are scientific and teaching media can solve effectively } \\
\text { the key points and difficulties of teaching }\end{array}$ \\
\hline & & Information technology teaching means are rich, reasonable and effective. \\
\hline & teaching mode & Using information technology to realize online and offline teaching mode \\
\hline & \multirow[t]{3}{*}{ teaching effect } & Students' grades have been improved \\
\hline & & Stimulate students' interest in learning \\
\hline & & Cultivate students' ability of independent thinking \\
\hline
\end{tabular}


The statistical analysis of these data is helpful for teachers to grasp the teaching effect of curriculum implementation, analyze the influencing factors and existing problems of professional curriculums.

\subsection{The Determination of Students' Teaching Evaluation Index}

The evaluation of students' learning is a diversified evaluation method, including process evaluation and summative evaluation. The process evaluation index accounts for $60 \%$ and summative evaluation index accounts for $40 \%[6]$. The combination of process evaluation and summative evaluation can investigate students' learning situation from many aspects and perspectives. The process evaluation is mainly composed of online learning and offline learning, and the summative evaluation is composed of students' mid-term and final examinations. Online learning mainly refers to that students learn the course content and test through the platform, and teachers understand the mastery of students' knowledge points through the analysis of students' pre-class test results. Online learning is composed of pre-class preview and pre-tests, post-tests, resource learning, online homework and the number of times to participate in discussion; offline learning mainly refers to classroom learning, which aims to promote the ability of students' learning, cultivate the ability to think about problems and team spirit. It is composed of attendance rate, the number of classroom speeches, group PK and theoretical test. Students need to evaluate curriculum design, curriculum content and teaching methods after class. After collecting and analyzing on the platform, teachers improve the teaching design. Table 2 shows the composition of students' learning evaluation index.

Table 2. Student learning evaluation index

\begin{tabular}{|c|c|c|}
\hline Index category & $\begin{array}{l}\text { One-level } \\
\text { index }\end{array}$ & Two-level index \\
\hline \multirow{13}{*}{$\begin{array}{l}\text { Student learning } \\
\text { evaluation index }\end{array}$} & \multirow{6}{*}{$\begin{array}{l}\text { Online } \\
\text { learning }\end{array}$} & Study time \\
\hline & & Study frequency \\
\hline & & $\begin{array}{c}\text { preview the lessons } \\
\text { before class }\end{array}$ \\
\hline & & Test before class \\
\hline & & Network work \\
\hline & & $\begin{array}{c}\text { Participate in the } \\
\text { discussion }\end{array}$ \\
\hline & \multirow{5}{*}{$\begin{array}{l}\text { Offline } \\
\text { learning }\end{array}$} & Attendance \\
\hline & & $\begin{array}{c}\text { Answer questions } \\
\text { in class }\end{array}$ \\
\hline & & Classroom exercise \\
\hline & & Theory test \\
\hline & & Group PK \\
\hline & \multirow{2}{*}{$\begin{array}{l}\text { Learning } \\
\text { results }\end{array}$} & Interim test grads \\
\hline & & Final grads \\
\hline
\end{tabular}

\section{APPLICATION OF TEACHING EVALUATION METHOD}

The diversified teaching evaluation method in higher vocational colleges has been applied in the course of "virtualization technology" of cloud computing technology and application major in Beijing Information Technology College. In the process of teaching, teachers' teaching is evaluated. The student evaluation results of teaching organization are listed only in this paper, and the feedback of students is shown in Figure 2. It can be seen from the figure that $74 \%$ of the students are satisfied with the teacher's guidance and interactive activities, indicating that the students are more satisfied with the existing guidance.

Teachers provide us with rich online discussion and classroom interaction activities, and give timely teaching guidance and help.

A strongly agree $\mathrm{B}$ agree $\mathrm{C}$ neutrality $\mathrm{D}$ disagree $\mathrm{E}$ strongly disagree

According to the feedback data of students, teachers can explore more ways of communication and interaction to improve students' curriculum stickiness. For example, try to achieve face-to-face communication by live guidance.

Teaching organization evaluation

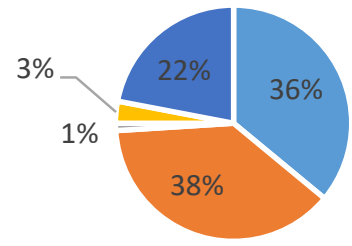

$$
\begin{aligned}
& \text { - agree } \quad \text { - strongly agree } \\
& \text { - strongly disagree } \quad \text { - disagree } \\
& \text { - neutrality }
\end{aligned}
$$

Figure 2 Statistics of teaching organization evaluation

In terms of student evaluation, figure 3 shows the test scores of students randomly selected from a certain exam. As can be seen from Figure 3 , the pass rate ( $\geq 60$ points) has reached $80.95 \%$, the good rate ( $\geq 80$ points) has reached $54.76 \%$, and the excellent rate ( $\geq 90$ points) has reached $47.62 \%$. This shows that most students have mastered the course content. The students who fail should find the distance from the classroom performance and remind them. 


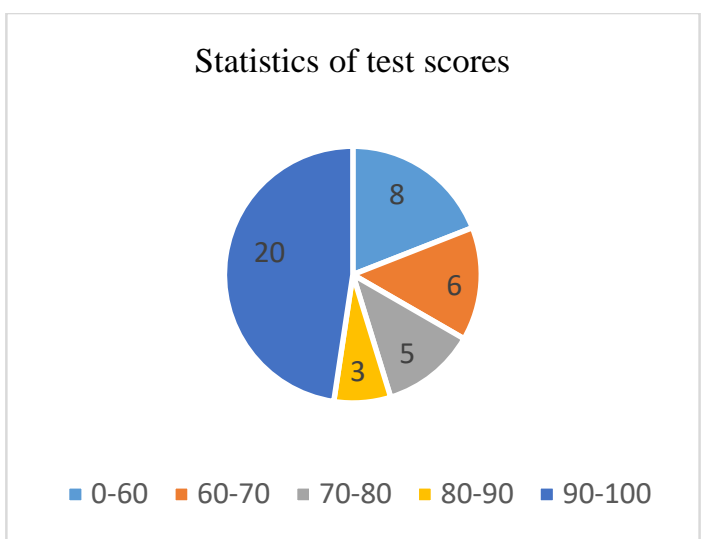

Figure 3 Statistics of test scores

Through the implementation of teaching evaluation method, both teachers and students can analyze the shortcomings and advantages from the specific data. Teachers adjust teaching strategies in time, and students adjust learning status in time to make up for the deficiencies.

\section{CONCLUSION}

Through more than two years of practical application, the student learning evaluation method of the diversified teaching evaluation method in higher vocational colleges can carry out a comprehensive, scientific, objective and accurate curriculum learning evaluation for students, teachers can timely grasp the students' learning status, effectively teach, and cultivate students' ability to think about problems, so as to promote students' all-round development. Teachers' teaching evaluation method can make a comprehensive evaluation of teachers' teaching. According to students' feedback, it can constantly improve teaching methods and enhance teachers' teaching ability.

\section{ACKNOWLEDGMENTS}

This work is supported by grants from Teaching Reform project of Vocational Education of Beijing Municipal Education Commission (No. 2018-139) and Teaching Reform Research project of Inner Mongolia Agricultural University (JGYB201924).

\section{REFERENCES}

[1] Haiyan Liu, Xiaomin Liu, Ting Chen, Yi Liu. Research Overview of the Informative Teaching Approach Under cloud computing Environment. 2020 International Conference on Education Elearning and Social Science, 2020:7-11.

[2] Zhang Lishan, Feng Shuo, Li Tingting. Formal Modeling and Intelligent Computing for Classroom Instruction and Assessment, 2021,33(1):13-25.

[3] Liu Haiyan, Liu Xiaomin, Guo Li .Online Teaching Practice Based on Intelligent Vocational Education
Platform and WeChat Group -Take "Virtualization Technology" Course as an Example, Modern Information Technology, 2020,4(9):110116.

[4] Liu Juan, Xiang Linchuan, Ke Changjian etc . Research on the practice and development of teaching evaluation in Colleges and Universities - Take seven universities under the Ministry as examples, Journal of Higher Education, 2021,(04):11-15.

[5] Liu, Haiyan, Liu Xiaomin. Practical research on the blended teaching of the higher vocational computer professional course-case study of virtualization technology, Journal of Indian Pulp and Paper Technical Association ,2018,30(2):367-373

[6] Su Mingfeng, Huang HuiXiong, Ning Henan. Construction of blended learning evaluation system in cloud computing environment, Higher Education Online, 2019,868: 143-144. 